Jan Löhdefink

\title{
Zeiten des Teufels
}

Teufelsvorstellungen und Geschichtszeit in frühreformatorischen Flugschriften (1520-1526)

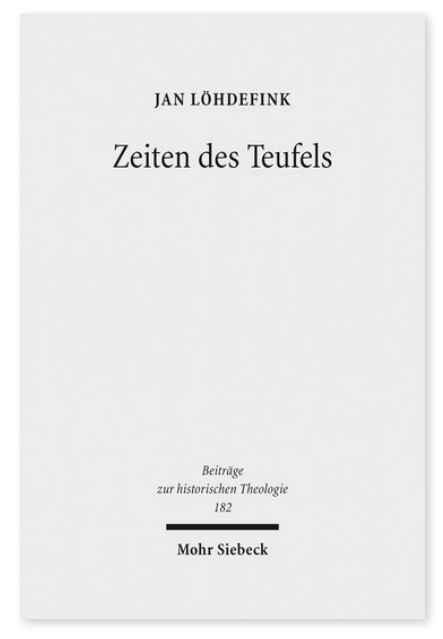

2016. XI, 412 Seiten. BHTh 182

ISBN 978-3-16-154489-7

DOI 10.1628/978-3-16-154489-7

eBook PDF 114,00€

ISBN 978-3-16-154449-1

Leinen $114,00 €$
Jan Löhdefink beschäftigt sich mit der Veränderung der Teufelsvorstellungen in der frühen Reformationszeit und deren Auswirkungen auf das Zeitbewusstsein. Er beschreibt die reformatorische Neumodulation der Trias von

Vergangenheitsdeutung, Gegenwartsverständnis und Zukunftsperspektive, welche gerade in ihrer scharfen polemischen Kontrastierung mit konkurrierenden Entwürfen die eigenen Konstitutionsbedingungen der Zeitwahrnehmung zu erkennen gibt und auf einen grundlegenden Wandel des Zeitverständnisses verweist. Gemeinhin werden die Teufelsvorstellungen den rückwärtsgewandten Gehalten der Reformation zugeschrieben - kaum ein anderer Traditionsbestand gilt als derart »unmodern« wie der Teufel. Mit Blick auf die den spezifisch reformatorischen Teufelsvorstellungen inhärente Neukonfiguration der zeitgenössischen Temporalstrukturen jedoch verkehrt sich der Befund, wenn gerade die Reflexionsgestalt des Teufels zum Konstituens einer neuen, in die Moderne weisenden Zeitwahrnehmung avanciert: So »unmodern« der Teufel der Neuzeit auch erscheinen mag - für ihre Genese kommt ihm eine Schlüsselstellung zu.

Jan Löhdefink Geboren 1974; 1994-2002 Studium der Ev. Theologie und Geschichtswissenschaft; 2010-15 Studienrat in Hamburg, seit 2015 in Emden.
Jetzt bestellen:

https://mohrsiebeck.com/buch/zeiten-des-teufels-9783161544897?no_cache=1

order@mohrsiebeck.com

Telefon: +49 (0)7071-923-17

Telefax: +49(0)7071-51104 